\title{
MicroRNA miR-93-5p regulates expression of IL-8 and VEGF in neuroblastoma SK-N-AS cells
}

\author{
ENRICA FABBRI ${ }^{1}$, GIULIA MONTAGNER $^{1}$, NICOLETTA BIANCHI $^{1}$, ALESSIA FINOTTI $^{1}$, MONICA BORGATTI $^{1}$, \\ ILARIA LAMPRONTI $^{1}$, GIULIO CABRINI ${ }^{2}$ and ROBERTO GAMBARI ${ }^{1}$ \\ ${ }^{1}$ Department of Life Sciences and Biotechnology, I-44121 Ferrara; ${ }^{2}$ Department of Pathology and Diagnostics, \\ University-Hospital, I-37126 Verona, Italy
}

Received July 22, 2015; Accepted July 27, 2015

DOI: $10.3892 /$ or.2016.4676

\begin{abstract}
The role of the microRNA miR-93-5p on the secretome profile and the expression levels of vascular endothelial growth factor (VEGF) and interleukin-8 (IL-8) was investigated in the neuroblastoma SK-N-AS cell line by Bio-Plex analysis and RT-qPCR. The results indicate that VEGF and IL-8 are the major miR-93-5p molecular targets. This conclusion was based on in vitro transfection with pre-miR-93-5p and anti-miR-93-5p; these treatments inversely modulated both VEGF and IL-8 gene expression and protein release in the neuroblastoma SK-N-AS cell line. Computational analysis showed the presence of miR-93-5p consensus sequences in the 3'UTR region of both VEGF and IL-8 mRNAs, predicting possible interaction with miR-93-5p and confirming a potential regulatory role of this microRNA.
\end{abstract}

\section{Introduction}

Neuroblastoma is the most common heterogeneous extracranial neoplastic disease of childhood, developing from immature nerve cells found in several areas of the body or where groups of nerve cells exist (1). The metastatic phenotype of neuroblastoma is associated to activation of several genes, some of which are deeply involved in angiogenesis $(2,3)$. Among these proteins, interleukin-8 (IL-8; or CXCL8) is known to be a major promoter of angiogenesis and invasive-

Correspondence to: Professor Roberto Gambari or Dr Enrica Fabbri, Department of Life Sciences and Biotechnology, University of Ferrara, Via Fossato di Mortara, 74, I-44121 Ferrara, Italy

E-mail: gam@unife.it

E-mail: enrica.fabbri@unife.it

Abbreviations: miR, microRNA; IL, interleukin; VEGF, vascular endothelial growth factor; GM-CSF, granulocyte-macrophage colonystimulating factor; G-CSF, granulocyte-colony stimulating factor; IP-10, interferon gamma-induced protein 10; MCP-1, monocyte chemotactic protein 1; PCR, polymerase-chain reaction; RT, reverse transcription; RT-qPCR, RT-quantitative PCR

Key words: microRNA, interleukin-8, vascular endothelial growth factor, neuroblastoma ness of human neuroblastomas (4). Another protein firmly involved in angiogenesis of neuroblastoma is vascular endothelial growth factor (VEGF) $(5,6)$. As expected, one of the control levels is transcription-related to the interaction between IL-8 and VEGF promoters and different transcription factors, such as NF- $\mathrm{B}$, AP-1 and C-EBP/NF-IL-6 (7-12). In addition, the expression of IL- 8 and VEGF genes may be under the control of epigenetic mechanisms, such as those regulated by microRNAs in cancer, differentiation and inflammatory processes (13-23).

MicroRNAs (miRs) are endogenous non-protein coding RNA molecules, from 19 to 25 nucleotides long, that regulate specifically mRNAs (24) altering protein levels, by inhibiting the ability of the ribosome to 'translate' the mRNA. MicroRNAs can increase mRNA degradation or block the translation to protein with a mechanism depending on the level of complementarity to mRNAs within the RISC complex (25). Considering that a single miR has many mRNA targets and that a single mRNA may be targeted by several microRNAs, it is calculated that a broad segment of the protein-coding genome is under their regulation in any type of biological or pathophysiological process, including differentiation, cell cycle and apoptosis. Accordingly, alteration of miR regulation can be associated to different diseases, including cancer (26-28).

Among the microRNAs, miR-93-5p is clearly demonstrated in a variety of cellular systems to be involved in post-transcriptional regulation of IL-8 and VEGF gene expression (15,29-31). For instance, we found that the effects of bacterial challenge activating IL- 8 gene transcription in epithelial cells are downregulated by miR-93-5p (29). On the other hand, miR-93-5p has been found involved also in the downregulation of VEGF expression $(30,31)$.

The aim of the present investigation was to study the effects of pre-miR-93-5p and anti-miR-93-5p on the secretome of a neuroblastoma cell line, in order to compare results studying IL-8 and VEGF expression with the data obtained on other chemokines, cytokines and growth factors.

\section{Materials and methods}

Neuroblastoma cell line and culture conditions. The SK-N-AS neuroblastoma cell line, obtained from bone marrow brain metastasis, was purchased from Sigma (Sigma-Aldrich, 
St. Louis, MO, USA) and cultured in humidified atmosphere of $5 \% \mathrm{CO}_{2}$ /air in RPMI-1640 medium (Life Technologies, Monza, Italy) supplemented with $10 \%$ fetal bovine serum (FBS; Celbio, Milan, Italy), 10,000 U/ml penicillin and $10 \mathrm{mg} / \mathrm{ml}$ streptomycin (Sigma-Aldrich) (32). To verify possible effects on proliferation, cell growth was monitored determining the cell number/ml using a Z2 Coulter Counter (Coulter Electronics, Hialeah, FL, USA).

Transfection with pre-miR and anti-miR molecules. SK-N-AS cells were seeded at $2.5 \times 10^{5} / 500 \mu \mathrm{l}$ into 12 -wells plate and transfected with $200 \mathrm{nM}$ anti-miR-93-5p (AM:10951), pre-miR-93-5p (PM:10951) and miR-negative controls (AM:17110, AM:17010) (Ambion, Applied Biosystems, Foster City, CA, USA) complexed with Lipofectamine RNAiMAX (Invitrogen, Life Technologies, Carlsbad, CA, USA). After $48 \mathrm{~h}$, cell supernatants were collected and total RNA was isolated using TRI Reagent ${ }^{\mathrm{TM}}$ (Sigma Aldrich) and immediately converted to cDNA.

Quantification of IL-8 and VEGF mRNA content. Total RNA (300 ng) was reverse-transcribed to cDNA using random primers (Applied Biosystems). IL-8 and VEGF mRNAs analyzed with RT-qPCR were quantified by iQ SYBR-Green Supermix (Bio-Rad Laboratories, Hercules, CA, US) using the IL-8 reverse (5'-TTA TGA ATT CTC AGC CCT CTT CAA AAA CTT CTC-3') and forward (5'-GTG CAG TTT TGC CAA GGA GT-3') primers and by VEGF TaqMan Gene Expression Assays (HS00173626_m1), and normalized to the calibrator genes RPL13A (code HS03043885_g1) and 18S rRNA (code 4310893E) (all from Applied Biosystems) according to the manufacturer's instructions. These assays were carried out with a CFX96 Touch $^{\mathrm{TM}}$ Real-Time PCR Detection System (Bio-Rad Laboratories). Relative quantification of gene expression was performed using the comparative threshold $\left(\mathrm{C}_{\mathrm{T}}\right)$ method. Changes in mRNA expression level were expressed as fold-change over Lipofectamine RNAiMAX treated samples.

Bio-Plex analysis. Cytokines, chemokines and growth factors in tissue culture supernatants released from the cells under analysis were measured by Bio-Plex Pro Human Cytokine 27-Plex Assay (\#M50-0KCAF0Y; Bio-Rad Laboratories) as described by the manufacturer $(33,34)$. The Bio-Plex cytokine assay is designed for the multiplex quantitative measurement of multiple cytokines in a single well using as little as $50 \mu 1$ of sample. Samples were analyzed on a Bio-Rad 96-well plate reader using the Bio-Plex Suspension Array System and Bio-Plex Manager software (Bio-Rad Laboratories) $(33,34)$.

Analysis of apoptosis and cell cycle. SK-N-AS neuroblastoma cells were treated for $48 \mathrm{~h}$ with $200 \mathrm{nM}$ pre-miR-93-5p, antimiR-93-5p and miR negative controls, then apoptosis was detected with Annexin V and Dead Cell and Caspase 3/7 Muse assays. Cell cycle was analyzed with the Muse Cell Cycle kit (EMD Millipore Corporation, Hayward, CA, USA) using the Muse Cell Analyzer instrument (Millipore Corporation), according to the instructions supplied by the manufacturer. Data from prepared samples were acquired and recorded utilizing dedicated programs (Millipore) (35).
Thermodynamic structure prediction and interaction. Analysis of RNA secondary structure was performed using ViennaRNA Web Services, RNA fold server, Institute of Theoretical Chemistry, University of Vienna (http://rna.tbi. univie.ac.at/cgi-bin/RNAfold.cgi) (36). RNA sequences were obtained from UCSC Genome Bioinformatics (http://genome. ucsc.edu/) (37) and microRNA sequence from miRBase, the microRNA database, University of Manchester (http://www. mirbase.org/) $(38,39)$. The interactions between mRNAs and miRNA were predicted with microrna.org, Memorial SloanKettering Cancer Center (http://www.microrna.org/microrna/ home.do) (40), with TargetScan 6.2, Whitehead Institute for Biomedical Research (http://www.targetscan.org/) (41) and miRWalk 2.0 Heidelberg University (http://www.umm.uniheidelberg.de/apps/zmf/mirwalk/) (42).

Statistical analysis. Results are expressed as mean \pm standard deviation (SD). Comparisons between groups were made using paired Student's t-test. Statistical significance was defined as $\mathrm{p}<0.05$ (statistically significant) and $\mathrm{p}<0.01$ (highly statistically significant).

\section{Results}

Secretomic profile in $S K-N-A S$ neuroblastoma cells treated with pre-miR-93-5p and anti-miR-93-5p: miR-93-5p dependency in genes involved in inflammation. In order to verify whether miR-93-5p regulates pro-inflammatory genes, a 27-plex cytokine assay was carried out using supernatants collected from 2-days cultured SK-N-AS neuroblastoma cells seeded at the initial concentration of $5 \times 10^{5}$ cells $/ \mathrm{ml}$. A preliminary analysis of the secretome of SK-N-AS cells demonstrates a strong difference with respect to protein release. Proteins released with highest efficiency $(>10 \mathrm{pg} / \mathrm{ml})$ were IL-7, IL-8, IL-15, GM-CSF, G-CSF, IP-10, MCP-1 and VEGF (data not shown) and were considered in our analysis. To study miR93-5p dependency, SK-N-AS cells were cultured in the absence or in the presence of pre-miR-93-5p and anti-miR-93-5p. Fig. 1 shows the first set of data firmly demonstrating that these treatments have no major effects on SK-N-AS cellular apoptosis (Fig. 1A and B), cell growth (Fig. 1C) and cell cycle (Fig. 1D). As far as the effects of pre-miR-93-5p and anti-miR-93-5p treatments on secretome, in some cases we found a relevant inverse correlation between relative content of secreted proteins in cells pre-transfected with pre-miR-93-5p and the fold increase of secretion following anti-miR-93-5p treatment (Fig. 2A). We applied an algorithm for determining the miR-93-5p dependency index (miR-93 $3_{\text {INDEX }}$ ) of SK-N-AS cells, based on the determination of the treated/untreated fold values as follows: miR-93 $3_{\text {INDEX }}=1$ - [fold (pre-miR-93 treatment)/fold (anti-miR-93 treatment)]. Following this algorithm we expected high values of miR-93 $3_{\text {INDEX }}$ for the genes whose expression was regulated by miR-93. The miR-93 $3_{\text {INDEX }}$ values for the different cytokines/chemokines/growth factors studied are indicated in Fig. 2B. Taken together, these results strongly suggest that the two genes displaying the highest levels of sensitivity to miR-93-5p are IL-8 and VEGF. Interestingly, IL-8 and VEGF are demonstrated to play a significant role in the late stages of neuroblastoma progression, including interaction with the microenvironment leading to angiogenesis $(2-6,8)$. 
A

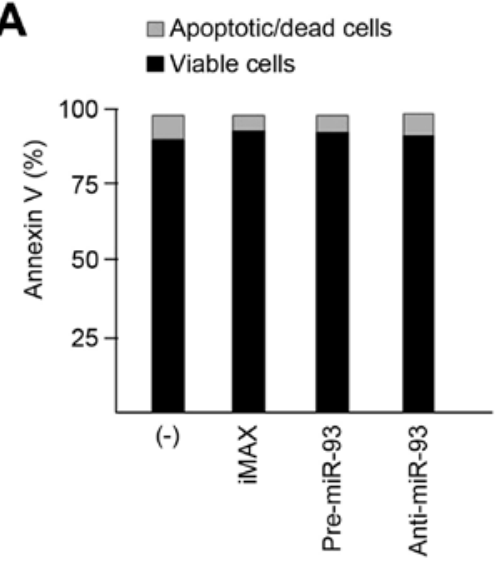

C

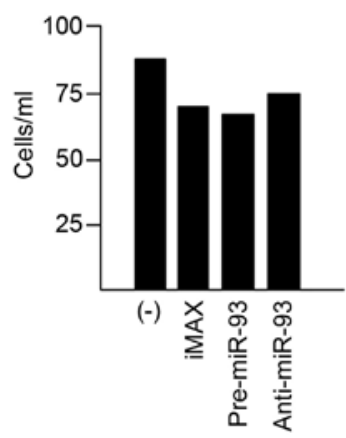

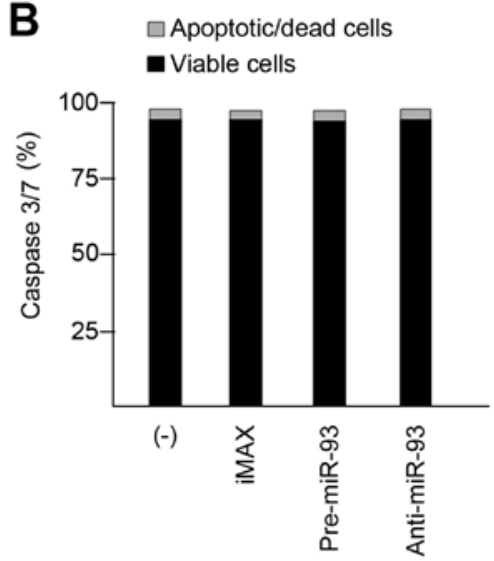

D

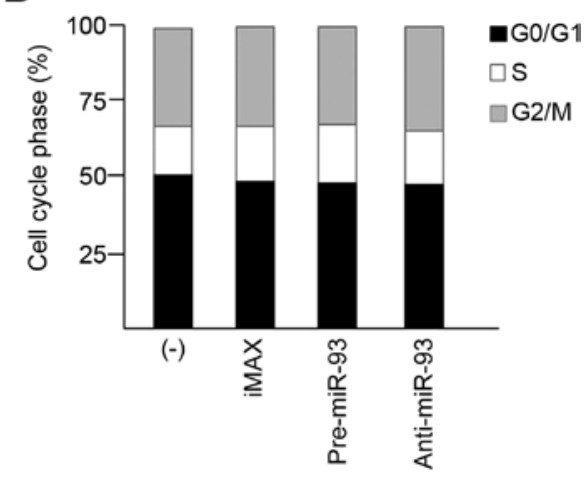

Figure 1. Effects of treatment of SK-N-AS cells with anti-miR-93-5p and pre-miR-93-5p on apoptosis, cell growth and cell cycle. SK-N-AS cells were treated with Lipofectamine RNAiMAX (the transfection reagent), anti-miR-93-5p and pre-miR-93-5p and apoptosis was analyzed using the Annexin V (A) and the Caspase 3/7 (B) kits. The effects of the treatments on cell growth and distribution of the cells through the G0/G1, S and G2/M cell cycle phases are shown in panels $\mathrm{C}$ and $\mathrm{D}$, respectively.

A

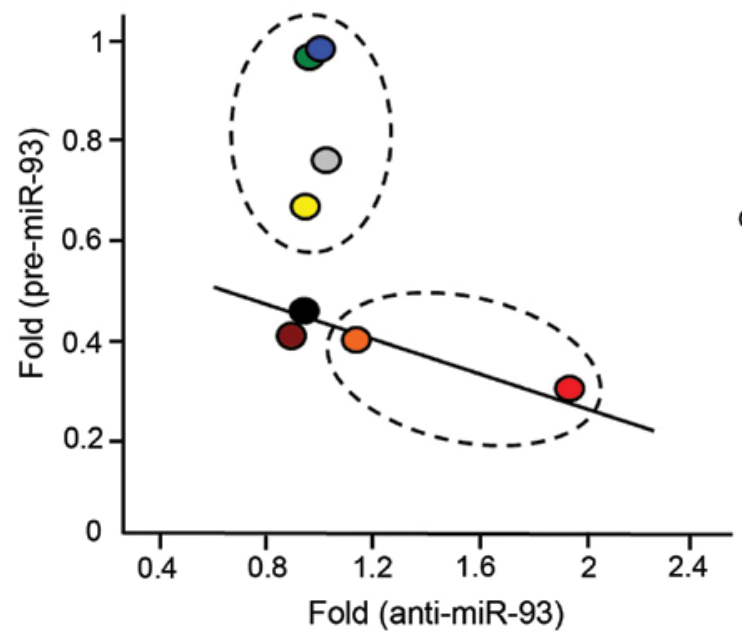

B
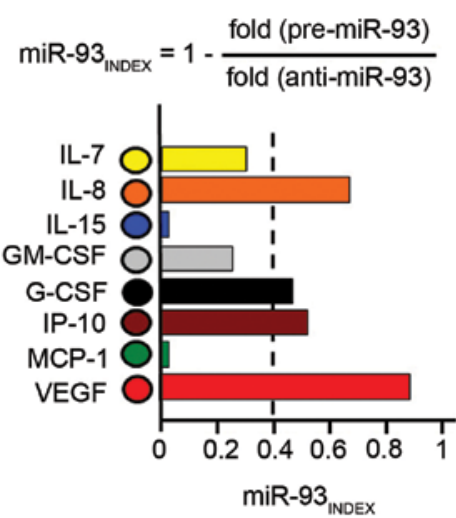

Figure 2. Secretome profile of SK-N-AS cells. (A) Fold expression after treating SK-N-AS cells with anti-miR-93-5p and pre-miR-93-5p. The data generating this panel were obtained by Bio-Plex analysis. Dotted circles identify proteins released with high efficiency after treatment with anti-miR-93-5p (IL-8 and VEGF) and pre-miR-93-5p (MCP-1, IL-15, GM-CSF, IL-7). (B) miR-93 ${ }_{\text {INDEx }}$ calculated for IL-7, -8 and -15, GM-CSF, G-CSF, IP-10, MCP-1 and VEGF. The algorithm used to calculate the miR-93 $93_{\text {INDEX }}$ is shown in the upper part of the panel.

IL-8 and VEGF mRNAs are putative targets of miR-93-5p. Figs. 3 and 4 show the possible interactions between miR-93-5p and miR-93-5p binding sites located within the IL-8 mRNA (Fig. 3) and VEGF mRNA (Fig. 4) sequences.
The miR-93-5p target sequences of IL-8 and VEGF mRNAs are shown, indicating possible base-pairing with miR-93-5p. These predicted analyses support the hypothesis that both IL-8 and VEGF mRNAs are targets of miR-93-5p. 


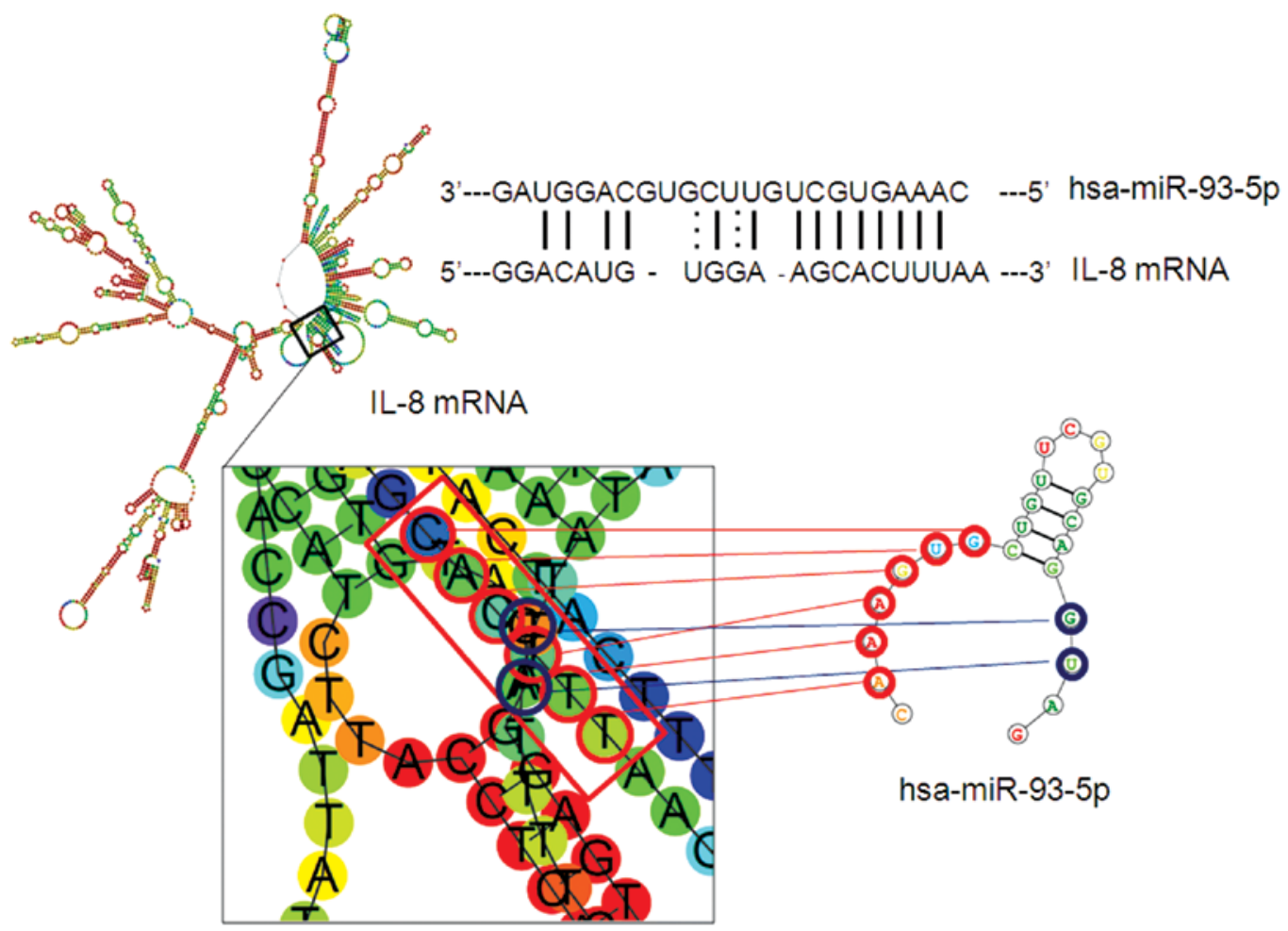

Figure 3. Interactions of miR-93-5p with IL-8 mRNA. Predicted secondary structures of IL-8 mRNA and of hsa-miR-93-5p was based on ViennaRNA web Service (http://rna.tbi.univie.ac.at/cgi-bin/RNAfold.cgi). The miRNA-target interaction is predicted by databases available online (http://www.microrna.org/ microrna/home.do; http://www.targetscan.org; http://www.umm.uni-heidelberg.de/apps/zmf/mirwalk/). Magnification is also shown of the portion of IL-8 mRNA involved in possible interactions with the seed region of the lowest energy hsa-miR-93-5p potential stem loops.

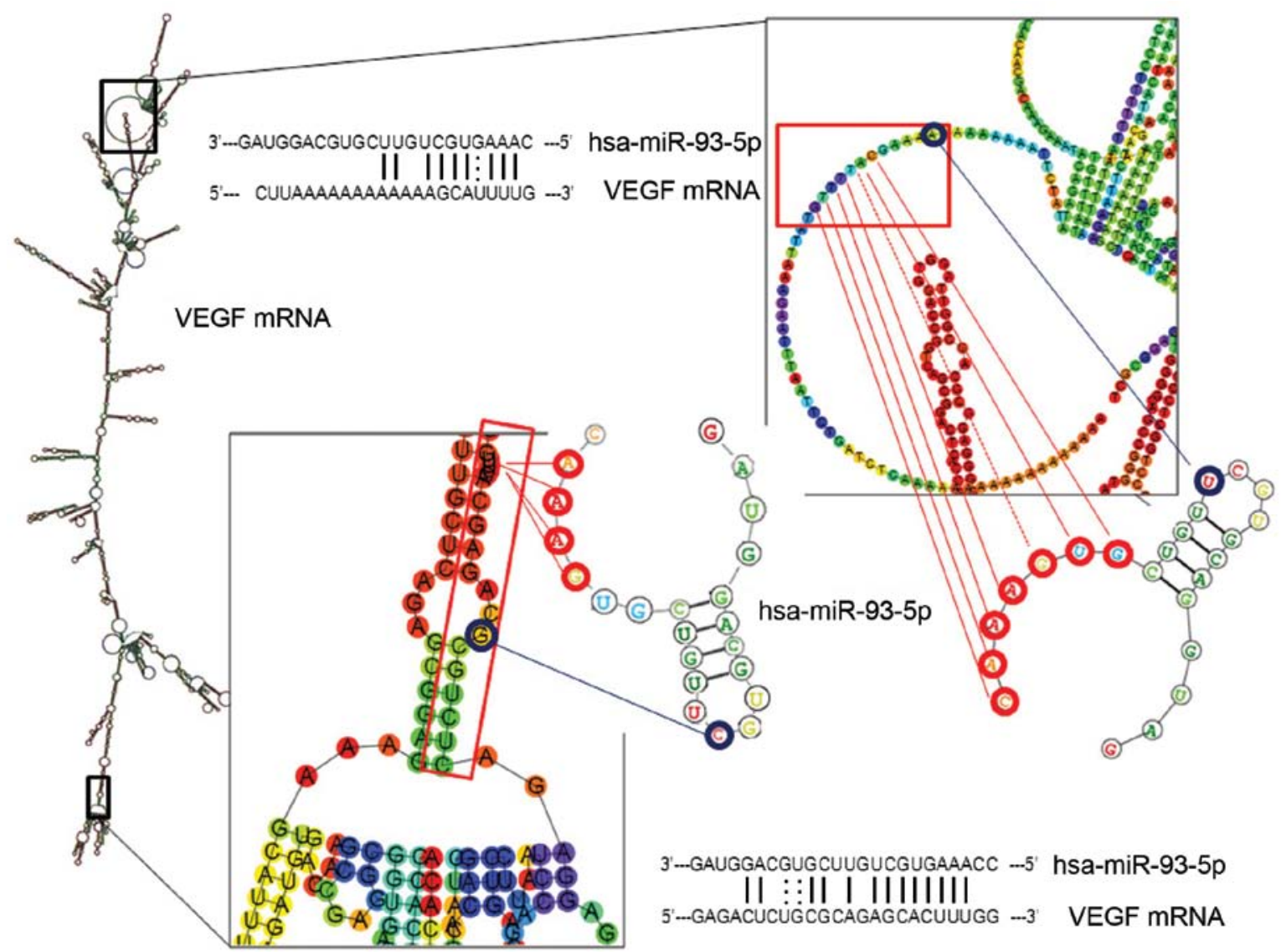

Figure 4. Interactions of miR-93-5p with VEGF mRNA. Predicted secondary structures of VEGF mRNA and their interactions with hsa-miR-93-5p (for details see legend to Fig. 3). Magnification is also shown of the two portions of VEGF mRNA involved in possible interactions with the seed region of the lowest energy hsa-miR-93-5p potential stem loops. 
A
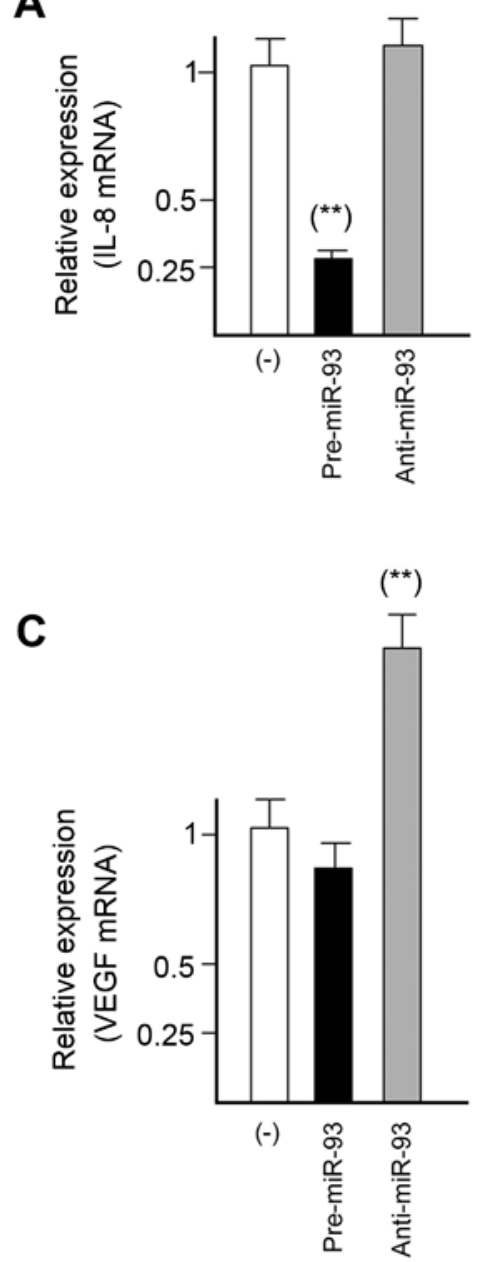

B

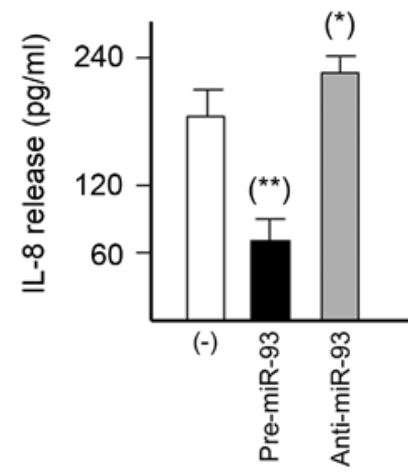

D

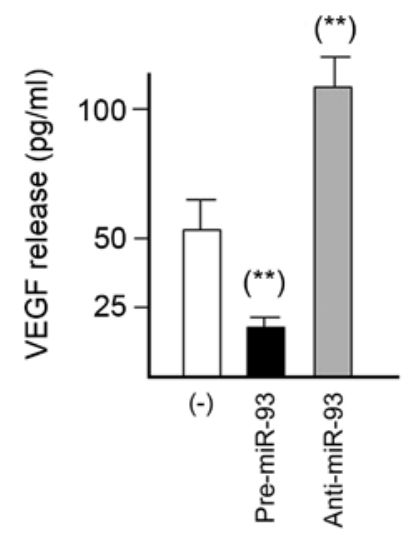

Figure 5. Effects of the treatments of neuroblastoma SK-N-AS cells with pre-miR-93-5p and anti-miR-93-5p. (A) IL-8 and (C) VEGF mRNAs were quantified by RT-qPCR analysis; (B) IL-8 and (D) VEGF released proteins were quantified by Bio-Plex analysis. RNA was isolated from cultures after $48 \mathrm{~h}$ in vitro treatment and analyzed by RT-qPCR. Internal RT-qPCR controls were RPL13A and 18S for IL-8 and VEGF mRNAs. Data are in all cases reported in comparison to SK-N-AS cells treated with control scrambled sequences. Results represent the average \pm SD of at least three independent experiments. " $p<0.05 ;{ }^{* *} \mathrm{p}<0.01$.

Alteration of IL-8 gene and VEGF gene expression in $S K-N-A S$ cells transfected with pre-miR-93-5p and anti-miR-93-5p. Fig. 5 shows experiments in which pre-miR-93-5p and antimiR-93-5p have been transfected to SK-N-AS cells and gene expression of IL-8 (Fig. 5A and B) and VEGF (Fig. 5C and D) gene expression was determined by RT-qPCR (Fig. 5A and C) and Bio-Plex analysis of released proteins (Fig. 5B and D).

The results reported regarding the effects on IL-8 gene expression, demonstrate that when SK-N-AS neuroblastoma cells are transfected with a pre-miR-93-5p RNA a decrease of IL-8 mRNA occurs (Fig. 5A). This is confirmed by the Bio-Plex analysis performed on cell growth medium, in which a sharp decrease of released IL-8 protein was found in premiR-93-5p treated SK-N-AS cell cultures (Fig. 5B). Despite the fact that pre-miR-93-5p effects on VEGF mRNA were minor (Fig. 5C), the same trend was found for VEGF release, as shown in Fig. 5D, demonstrating that VEGF secretion is sharply decreased in pre-miR-93-5p treated SK-N-AS cells.

In order to further sustain the possible involvement of miR93-5p on IL-8 and VEGF expression, we determined whether treatment of the SK-N-AS neuroblastoma cell line with antimiR against miR-93-5p led to increased IL-8 and VEGF. The SK-N-AS neuroblastoma cells were transfected with
anti-miR-93-5p and the expression of IL-8 and VEGF mRNA content and protein secretion were analyzed by RT-qPCR and Bio-Plex assays, respectively. The anti-miR-93-5p was administrated at the concentration of $200 \mathrm{nM}$ with the Lipofectamine RNAiMAX transfection reagent. We first demonstrated a $65.2 \pm 5.8$ reduction of the miR- $93-5 \mathrm{p}$ accumulation in SK-N-AS neuroblastoma cells treated with anti-miR-93-5p (data not shown). Fig. 5 (panels A and B) demonstrates that the forced downregulation of miR-93-5p is accompanied by a slight increase of IL-8 mRNA (Fig. 5A) and a significantly higher release of IL-8 (Fig. 5B). In addition increased expression of VEGF mRNA (Fig. 5C) and VEGF release (Fig. 5D) was found in anti-miR-93-5p treated SK-N-AS cells. Altogether, the data shown in Fig. 5 are fully in agreement with the hypothesis of an involvement of miR-93-5p in IL-8 and VEGF gene expression in this tumor cell line.

\section{Discussion}

A first conclusion of the present study is that treatment of SK-N-AS cells with pre-miR-93-5p and anti-miR-93-5p leads to different effects on expressed cytokines/chemokines/growth factors. The data obtained are shown in Fig. 2, which demon- 
strates that miR-93-5p dependency was found for G-CSF and IP-10, but is particularly evident for IL-8 (index, 0.65) and VEGF (index, 0.85). As expected from data in Fig. 2, we found miR-93-5p binding sites in IL-8 and VEGF mRNAs (see the prediction analysis of interactions shown in Figs. 3 and 4), in agreement with the found miR-93 $3_{\text {INDEX }}$.

The final conclusion of the present study is that the microRNA miR-93-5p is involved in the control of the expression of the IL- 8 and VEGF genes in the neuroblastoma SK-N-AS cell line on the basis of the effects of different transfections with pre-miR-93-5p or anti-miR-93-5p.

The effects of these treatments, showed in Fig. 5, were analyzed by RT-qPCR (looking at the IL- 8 and VEGF mRNA content) and by Bio-Plex analysis (looking at IL-8 and VEGF protein secretion).

In addition to basic science implications, our data may be of interest in applied biomedicine $(43,44)$, since we demonstrated that forced expression of miR-93-5p is able to reduce IL-8 and VEGF gene expression; therefore, molecules mimicking pre-miR-93-5p activity may be proposed to reduce IL- 8 and VEGF dependent angiogenesis in neuroblastomas.

\section{Acknowledgements}

This study was granted by CIB, by COFIN-2009 and by AIRC (IG 13575: peptide nucleic acids targeting oncomiR and tumor-suppressor miRNAs: cancer diagnosis and therapy). E.F. was a recipient of a CIB-funded fellowship.

\section{References}

1. Park JR, Bagatell R, London WB, Maris JM, Cohn SL, Mattay KK, Hogarty M; COG Neuroblastoma Committee: Children's Oncology Group's 2013 blueprint for research: Neuroblastoma. Pediatr Blood Cancer 60: 985-993, 2013.

2. Ribatti D, Marimpietri D, Pastorino F, Brignole C, Nico B, Vacca A and Ponzoni M: Angiogenesis in neuroblastoma. Ann NY Acad Sci 1028: 133-142, 2004.

3. Ribatti D: Anti-angiogenesis in neuroblastoma. Crit Rev Oncol Hematol 86: 212-221, 2013.

4. Eggert A, Ikegaki N, Kwiatkowski J, Zhao H, Brodeur GM and Himelstein BP: High-level expression of angiogenic factors is associated with advanced tumor stage in human neuroblastomas. Clin Cancer Res 6: 1900-1908, 2000.

5. Choudhury SR, Karmakar S, Banik NL and Ray SK: Targeting angiogenesis for controlling neuroblastoma. J Oncol 2012: $782020,2012$.

6. Shusterman S and Maris JM: Prospects for therapeutic inhibition of neuroblastoma angiogenesis. Cancer Lett 228: 171-179, 2005.

7. Megison ML, Gillory LA and Beierle EA: Cell survival signaling in neuroblastoma. Anticancer Agents Med Chem 13: 563-575, 2013.

8. Pistoia V, Bianchi G, Borgonovo G and Raffaghello L: Cytokines in neuroblastoma: From pathogenesis to treatment. Immunotherapy 3: 895-907, 2011.

9. Neuschäfer-Rube F, Pathe-Neuschäfer-Rube A, Hippenstiel S, Kracht $\mathrm{M}$ and Püschel GP: NF- $\kappa \mathrm{B}$-dependent IL-8 induction by prostaglandin $\mathrm{E}_{2}$ receptors $\mathrm{EP}_{1}$ and $\mathrm{EP}_{4}$. Br J Pharmacol 168: 704-717, 2013

10. Finotti A, Borgatti M, Bezzerri V, Nicolis E, Lampronti I, Dechecchi M, Mancini I, Cabrini G, Saviano M, Avitabile C, et al: Effects of decoy molecules targeting NF-kappaB transcription factors in cystic fibrosis IB3-1 cells: Recruitment of NF-kappaB to the IL-8 gene promoter and transcription of the IL-8 gene. Artif DNA PNA XNA 3: 97-296, 2012.

11. Khanjani S, Terzidou V, Johnson MR, Bennett PR: $\mathrm{NF}_{\kappa} \mathrm{B}$ and AP-1 drive human myometrial IL8 expression. Mediators Inflamm 2012: 504952, 2012.
12. Bezzerri V, Borgatti M, Finotti A, Tamanini A, Gambari R and Cabrini G: Mapping the transcriptional machinery of the IL-8 gene in human bronchial epithelial cells. J Immunol 187: 6069-6081, 2011

13. Wei T, Xu N, Meisgen F, Ståhle M, Sonkoly E and Pivarcsi A: Interleukin-8 is regulated by miR-203 at the posttranscriptional level in primary human keratinocytes. Eur J Dermatol: Apr 19, 2013 (Epub ahead of print).

14. Perng DW, Yang DM, Hsiao YH, Lo T, Lee OK, Wu MT, Wu YC and Lee YC: miRNA-146a expression positively regulates tumor necrosis factor- $\alpha$-induced interleukin- 8 production in mesenchymal stem cells and differentiated lung epithelial-like cells. Tissue Eng Part A 18: 2259-2267, 2012.

15. Chuang TD, Luo X, Panda H and Chegini N: miR-93/106b and their host gene, $M C M 7$, are differentially expressed in leiomyomas and functionally target $F 3$ and $I L-8$. Mol Endocrinol 26: 1028-1042, 2012.

16. Zhou R, Li X, Hu G, Gong AY, Drescher KM and Chen XM: miR-16 targets transcriptional corepressor SMRT and modulates NF-kappaB-regulated transactivation of interleukin-8 gene. PLoS One 7: e30772, 2012.

17. Bhattacharyya S, Balakathiresan NS, Dalgard C, Gutti U, Armistead D, Jozwik C, Srivastava M, Pollard HB and Biswas R: Elevated miR-155 promotes inflammation in cystic fibrosis by driving hyperexpression of interleukin-8. J Biol Chem 286: 11604-11615, 2011

18. Bhaumik D, Scott GK, Schokrpur S, Patil CK, Orjalo AV, Rodier F, Lithgow GJ and Campisi J: MicroRNAs miR-146a/b negatively modulate the senescence-associated inflammatory mediators IL-6 and IL-8. Aging 1: 402-411, 2009.

19. Khan FH, Pandian V, Ramraj S, Aravindan S, Herman TS and Aravindan N: Reorganization of metastamiRs in the evolution of metastatic aggressive neuroblastoma cells. BMC Genomics 16: 501, 2015.

20. Chen L, Li ZY, Xu SY, Zhang XJ, Zhang Y, Luo K and Li WP: Upregulation of miR-107 inhibits glioma angiogenesis and VEGF expression. Cell Mol Neurobiol: Jun 18, 2015 (Epub ahead of print).

21. Tsuchiya M, Kumar P, Bhattacharyya S, Chattoraj S, Srivastava M, Pollard HB and Biswas R: Differential regulation of inflammation by inflammatory mediators in cystic fibrosis lung epithelial cells. J Interferon Cytokine Res 33: 121-129, 2013.

22. Cabrini G, Fabbri E, Lo Nigro C, Dechecchi MC and Gambari R: Regulation of expression of $\mathrm{O}^{6}$-methylguanine-DNA methyltransferase and the treatment of glioblastoma (Review). Int J Oncol 47: 417-428, 2015.

23. Bianchi N, Finotti A, Ferracin M, Lampronti I, Zuccato C, Breveglieri G, Brognara E, Fabbri E, Borgatti M, Negrini M, et al: Increase of microRNA-210, decrease of raptor gene expression and alteration of mammalian target of rapamycin regulated proteins following mithramycin treatment of human erythroid cells. PLoS One 10: e0121567, 2015.

24. Sun K and Lai EC: Adult-specific functions of animal microRNAs. Nat Rev Genet 14: 535-548, 2013.

25. Berindan-Neagoe I, Monroig PC, Pasculli B and Calin GA: MicroRNAome genome: A treasure for cancer diagnosis and therapy. CA Cancer J Clin 64: 311-336, 2014.

26. Adams BD, Kasinski AL and Slack FJ: Aberrant regulation and function of microRNAs in cancer. Curr Biol 24: R762-R776, 2014.

27. Hayes J, Peruzzi PP and Lawler S: MicroRNAs in cancer: Biomarkers, functions and therapy. Trends Mol Med 20: 460-469, 2014.

28. Piva R, Spandidos DA and Gambari R: From microRNA functions to microRNA therapeutics: Novel targets and novel drugs in breast cancer research and treatment (Review). Int J Oncol 43: 985-994, 2013.

29. Fabbri E, Borgatti M, Montagner G, Bianchi N, Finotti A, Lampronti I, Bezzerri V, Dechecchi MC, Cabrini G and Gambari R: Expression of microRNA-93 and interleukin-8 during Pseudomonas aeruginosa-mediated induction of proinflammatory responses. Am J Respir Cell Mol Biol 50: 1144-1155, 2014.

30. Long J, Wang Y, Wang W, Chang BH and Danesh FR: Identification of microRNA-93 as a novel regulator of vascular endothelial growth factor in hyperglycemic conditions. J Biol Chem 285: 23457-23465, 2010. 
31. Fang L, Deng Z, Shatseva T, Yang J, Peng C, Du WW, Yee AJ, Ang LC, He C, Shan SW, et al: MicroRNA miR-93 promotes tumor growth and angiogenesis by targeting integrin- $\beta 8$. Oncogene 30: 806-821, 2011.

32. Sugimoto T, Tatsumi E, Kemshead JT, Helson L, Green AA and Minowada J: Determination of cell surface membrane antigens common to both human neuroblastoma and leukemia-lymphoma cell lines by a panel of 38 monoclonal antibodies. J Natl Cancer Inst 73: 51-57, 1984.

33. Borgatti M, Mancini I, Bianchi N, Guerrini A, Lampronti I, Rossi D, Sacchetti G and Gambari R: Bergamot (Citrus bergamia Risso) fruit extracts and identified components alter expression of interleukin 8 gene in cystic fibrosis bronchial epithelial cell lines. BMC Biochem 12: 15, 2011.

34. Penolazzi L, Lambertini E, Tavanti E, Torreggiani E, Vesce F, Gambari R and Piva R: Evaluation of chemokine and cytokine profiles in osteoblast progenitors from umbilical cord blood stem cells by BIO-PLEX technology. Cell Biol Int 32: 320-325, 2008.

35. Brognara E, Fabbri E, Bazzoli E, Montagner G, Ghimenton C, Eccher $\mathrm{A}$, Cantù $\mathrm{C}$, Manicardi $\mathrm{A}$, Bianchi N, Finotti A, et al: Uptake by human glioma cell lines and biological effects of a peptide-nucleic acids targeting miR-221. J Neurooncol 118 : 19-28, 2014.

36. Hofacker IL: Vienna RNA secondary structure server. Nucleic Acids Res 31: 3429-3431, 2003.

37. Kent WJ, Hsu F, Karolchik D, Kuhn RM, Clawson H, Trumbower $\mathrm{H}$ and Haussler D: Exploring relationships and mining data with the UCSC Gene Sorter. Genome Res 15: 737-741, 2005.
38. Griffiths-Jones S, Grocock RJ, van Dongen S, Bateman A and Enright AJ: miRBase: MicroRNA sequences, targets and gene nomenclature. Nucleic Acids Res 34: D140-D144, 2006.

39. Kozomara A and Griffiths-Jones S: miRBase: Annotating high confidence microRNAs using deep sequencing data. Nucleic Acids Res 42: D68-D73, 2014.

40. Betel D, Wilson M, Gabow A, Marks DS and Sander C: The microRNA.org resource: Targets and expression. Nucleic Acids Res 36 (Database): D149-D153, 2008.

41. Lewis BP, Shih IH, Jones-Rhoades MW, Bartel DP and Burge CB: Prediction of mammalian microRNA targets. Cell 115: 787-798, 2003.

42. Dweep H, Gretz N and Sticht C: miRWalk database for miRNAtarget interactions. Methods Mol Biol 1182: 289-305, 2014.

43. Fabbri E, Manicardi A, Tedeschi T, Sforza S, Bianchi N, Brognara E, Finotti A, Breveglieri G, Borgatti M, Corradini R, et al: Modulation of the biological activity of microRNA-210 with peptide nucleic acids (PNAs). ChemMedChem 6: 2192-2202, 2011.

44. Gambari R, Fabbri E, Borgatti M, Lampronti I, Finotti A, Brognara E, Bianchi N, Manicardi A, Marchelli R and Corradini R: Targeting microRNAs involved in human diseases: A novel approach for modification of gene expression and drug development. Biochem Pharmacol 82: 1416-1429, 2011. 